\title{
4 thematic patterns described the experience of placing a relative with Alzheimer's disease in a special care unit
}

Butcher HK, Holkup PA, Park M, et al. Thematic analysis of the experience of making a decision to place a family member with Alzheimer's disease in a special care unit. Res Nurs Health 2001 Dec;24:470-80.

\section{QUESTION: How do caregivers describe their experiences of deciding to place a relative with Alzheimer's disease (AD) in a special care unit (SCU)?}

\section{Design}

Semistructured interviews.

\section{Setting}

3 midwestern states in the US.

\section{Participants}

Source of funding: National Institute of Nursing.

For correspondence: Dr $H$ K Butcher, University of Iowa, College of Nursing, Iowa City, IA, USA. Howard-butcher@ uiowa.edu

A modified version of this abstract appears in Evidence-Based Mental Health.
30 family caregivers (80\% women; $70 \%$ children and $30 \%$ spouses of patients) of relatives with $\mathrm{AD}$ who lived in an SCU.

\section{Methods}

Caregivers were interviewed for 1-3 hours by clinical nurse specialists or a gerontology specialist. These semistructured interviews were videotaped and transcribed. Caregivers were asked to describe the type and quantity of care they had provided before the SCU placement; their involvement since placement; the quality of their relationship with the SCU staff; their evaluation of the care their relative was receiving; and their views about

\section{COMMENTARY}

As the population ages, more caregivers are called upon to care for an older adult. When possible, families prefer to keep an aging parent or spouse at home as long as they can. But there comes a time when it is impossible to do so. It is well known that family caregiving and caregivers' involvement do not end with the placement of an older family member in an institution. ${ }^{1}$

The thematic analysis by Butcher et al offers genuine insight into the experience of caregivers having to make the difficult decision to place a loved one with $\mathrm{AD}$ in an institution. It is one of the few studies looking into the process of making such a decision. The relatives were admitted to a unit specialising in the care of individuals with $\mathrm{AD}$. Because these units offer care tailored to the needs of people with $\mathrm{AD}$, the study findings should only be applied to similar care environments.

The study was carefully designed, and the methods were well described. The sample was drawn from a large 5 year quasi-experimental study. The independent analysis by 3 researchers increased the rigour of the research process. Despite purposively sampling for differences in sex, race, and relationship to the person with $\mathrm{AD}$, the findings were presented without taking these factors into account. The authors plan to do a new analysis to examine differences in decision making patterns according to these variables.

This study has important implications for nursing practice. The provision of help can lessen the anguish of the placement process for families. For example, when home care nurses identify caregivers who are moving toward making such a decision, supporting them during the process can positively influence the decision making experience. In addition, the provision of high quality nursing care to relatives in the SCU, helping family members remain involved in their relative's care, and referring family members for emotional support if necessary can help families to live with the decision to place a relative with $\mathrm{AD}$ in long term care.

Chantal D Caron, RN, PhD Assistant Professor, Department of Nursing Université de Sherbrooke Researcher, Research Centre on Aging Sherbrooke, Québec, Canada

1 Naleppa MJ. Families and the institutionalized elderly: a review. Journal of Gerontological Social Work 1996;27:87-111.

the SCU placement. They were also asked to describe their feelings at the time of making the decision and during the actual relocation of their relative, and what helped or hindered dealing with their feelings about the SCU placement. 3 reviewers independently used Luborsky's method of thematic analysis and QSR NUD*IST NVivo ${ }^{\circledR}$ qualitative software to code and analyse the transcripts. Data interpretation involved independent and then consensual (between researchers) interpretation of all aspects of the text.

\section{Main findings}

4 patterns emerged. Moving towards the unavoidable decision: caregivers gradually realised that something was wrong with their relative, which led to a breaking point at which they realised they could no longer care for their relative at home. Caregivers worried about their relative's safety, which resulted in a vigilance that was physically and emotionally draining. This breaking point was associated with a sense of finality. Struggling with the decision: caregivers described their anguish at the realisation they would need to place their relative in an SCU, and they used words like "difficult," "tough," "devastating," and "terrible." Feelings of guilt were often present. The presence or absence of support influenced the decision to place their relative in an SCU. Sharing the decision with the entire family lessened feelings of anguish and guilt. Seeking reassurance: caregivers needed to know that they had made the right decision, and the perception that their relative was receiving better care in the SCU gave them the best reassurance. This reassurance depended on their perception of the quality of care and their relative's level of contentment in the SCU. Sometimes the symptoms of $\mathrm{AD}$ made it difficult for caregivers to know how their relative was responding to the SCU. Caregivers observed and noticed how the staff interacted with residents in the SCU, and it was important to them that their relative appeared neat and clean. Caregivers experienced relief if they believed that their relative was receiving good care. Remaining connected: maintaining familial ties was a theme throughout the decision making process. Placement in the SCU marked a turning point and indicated the finality of the progression of AD. Caregivers remained involved in their relative's life by visiting often and taking their relative out.

\section{Conclusions}

Family caregivers who placed their relatives with Alzheimer's disease in a special care unit (SCU) described the anguish they felt in making the decision. Knowing their relative was receiving good care helped relieve their anguish. Caregivers maintained involvement in their relative's life in the SCU. 